\title{
EVALUATION OF TRIPLE ASSESSMENT FOR DIAGNOSIS OF BREAST CANCER IN A TERTIARY CENTRE
}

\author{
Kanwar Singh Goel ${ }^{1}$, Sapna Goel²
}

${ }_{1}^{1}$ Associate Professor, Department of General Surgery, SGT Medical College, SGT University, Budhera, Gurugram, Haryana. ${ }^{2}$ Senior Resident, Department of Pathology, SHKM Government Medical College, Nalhar, Mewat, Haryana.

\section{BACKGROUND}

ABSTRACT

Breast is a specialised accessory (modified sweat gland) of skin capable of milk secretion. Breast diseases may present with lump, nipple discharge or retraction, mastalgia etc. Benign lesion of breast commonly encountered are fibroadenosis, fibroadenoma, cyst, lactational breast abscess, non-lactational breast abscess etc. Malignant diseases of breast may present with a painless lump, mostly in the upper and outer quadrant of the breast. Pain is present only in about 10 percent cases. Nipple discharge is uncommon, but may be the only symptom. There may be enlargement, shrinkage or asymmetry of the affected breast. Sometimes the patient presents with metastatic symptoms like backache, chest pain, jaundice etc. Of all the diseases of breast the malignant diseases are the most dreaded, feared not only by the patients but also by the surgeons as well. If a lump is present in the breast, the woman feels threatened. Cancer phobia haunts her. She feels a sense of dissociation. In such cases, it is our duty to find out whether the lump is benign or malignant with as much certainty as possible. Triple assessment is the clinical assessment- history including age and examination; radiological imaging US/ mammography (after 40 years); cytological or historical analysis FNAC/core biopsy- pathology. Triple assessment is taken as positive if any of the three component is positive and negative only if all of its components are negative for malignancy. In view of this, we studied 180 cases of breast lump for evaluation by triple assessment to diagnose cancer.

The aim of the study is evaluation of triple assessment for diagnosis of breast cancer in a tertiary centre.

\section{MATERIALS AND METHODS}

The study was performed in Surgery Department in SGT Medical College, SGT University, Budhera, Gurugram, Haryana, over a period of 2 years 3 months from December 2015 to March 2018. A total of 180 patients were studied. A detailed history was taken. Focused clinical examination was done. USG, mammography and FNAC were performed. The results were evaluated.

\section{RESULTS}

The sensitivity and specificity of triple assessment when combined together was $100 \%$ and $99.3 \%$, respectively. Positive predictive value was $93.3 \%$, negative predictive value was $100 \%$, sensitivity was $100 \%$ and specificity was $99.3 \%$. P value was significant (0.000).

\section{CONCLUSION}

Triple assessment was found to be very useful in evaluating patients of breast lumps with an overall accuracy of $99.3 \%$.

\section{KEY WORDS}

Triple Assessment, Clinical Examination, Mammography, Ultrasonography, Fine-Needle Aspiration Cytology, Carcinoma.

HOW TO CITE THIS ARTICLE: Goel KS, Goel S. Evaluation of triple assessment for diagnosis of breast cancer in a tertiary centre. J. Evolution Med. Dent. Sci. 2018;7(21):2576-2580, DOI: $10.14260 /$ jemds/2018/580

\section{BACKGROUND}

Breast is a specialised accessory (Modified sweat gland) gland of skin capable of milk secretion. ${ }^{1}$ Breast diseases may present with lump, nipple discharge or retraction, mastalgia etc. Benign lesion of breast commonly encountered are fibroadenosis, fibroadenoma, cyst, lactational breast abscess, non-lactational breast abscess etc. A malignant breast disease may present as lump in the breast, which is hard and painless (most common). At least tumour should become $1 \mathrm{~cm}$ to be clinically palpable. Nipple discharge is the second common presentation. Ulceration and fungation, axillary lymph node enlargement, supraclavicular lymph node enlargement, chest

'Financial or Other Competing Interest': None.

Submission 09-04-2018, Peer Review 05-05-2018,

Acceptance 12-05-2018, Published 21-05-2018.

Corresponding Author:

Dr. Sapna Goel

Department of Pathology,

25/6, Opp. Bal Bhawan,

Gandhi Nagar, Scheme No. 6, Jind.

E-mail: kanwarsinghgoel@rediffmail.com

DOI: $10.14260 /$ jemds $/ 2018 / 580$ pain and haemoptysis, bone pain, tenderness and pathological fracture, pleural effusion, ascites, liver secondaries, secondary ovarian tumour are other presentations. Pain in the lump occurs in $10 \%$ cases. Various risk factors for carcinoma breast have been considered (Table 1). Breast cancer cases have been reported in ancient Egypt and found in Edwin Smith surgical Papyrus from 3000 to $2500 \mathrm{BC} .2,3$ Of all the disease of breast the malignant diseases is the most dreaded one, feared not only by the patients but also by the surgeons as well. If a lump is present in the breast, the woman feels threatened. Cancer phobia haunts her. She feels a sense of dissociation. In such cases it is our duty to find out whether the lump is benign or malignant with as much certainty as possible. Triple assessment i.e. clinical assessment- history including (age) and examination; radiological imaging US/ mammography (after 40 years); cytological or historical analysis FNAC/ core biopsypathology. Triple assessment is taken as positive if any of the three components is positive and negative only if all of its components are negative for malignancy. 


\section{Aims and Objectives}

To evaluate triple assessment for diagnosis of breast cancer in a tertiary centre.

\section{MATERIALS AND METHODS Study Site}

The study was performed in Surgery Department in SGT Medical College, SGT University, Budhera, Gurugram, Haryana, over a period of 2 years 3 months from December 2015 to March 2018.

\section{Study Design}

Prospective observational study.

\section{Selection of Subjects (Cases)}

A total of 180 patients were studied. Informed consent was taken for physical examination and investigations giving due respect to maintain the patient's privacy and keep them comfortable.

\section{Data Collection}

A detailed history about swelling (duration, rate of growth, any rapid growth), any swelling in opposite breast and axilla, details of pain, ulcer if any, nipple discharge, chest pain, cough, haemoptysis, h/o loss of weight, appetite, any pain in abdomen, back and limbs taken. Detailed past family, personal and treatment history taken. Focused clinical examination done. Ultrasonography was performed in supine or oblique position with ipsilateral arm above the head. The breast was scanned in transverse or sagittal or radial and anti-radial planes. USG is the better imaging modality to detect breast lesion in premenopausal women where mammography may not detect small lesion.4 Ultrasonography can detect the mass as solid or cystic. It is cheap and easily available. There is no radiation. But ultrasonography cannot detect small lesion less than $1 \mathrm{~cm}$ in diameter. The sensitivity, specificity, PPV and NPV of USG in detecting carcinoma breast is $55.6 \%, 97.7 \%, 83.3 \%$ and $91.5 \%$ respectively. ${ }^{5}$ Irregular margins, irregular internal echoes, irregular posterior shadowing, non-compressibility, ratio between anteroposterior to width (lateral/ horizontal) dimensions more than 1 are features of carcinoma. ${ }^{6}$ Mammography was done using craniocaudal and mediolateral views. The sensitivity, specificity, Positive predictive value (PPV) and Negative Predictive value (NPV) of mammography in detecting carcinoma breast is $77.8 \%, 97.7 \%, 87.5 \%$ and $95.6 \%$ respectively. 5 The characteristics of malignant lesion in mammography may be architectural distortion of breast tissue, duct dilation, dense stellate soft tissue mass with irregular margin and spiky projection, microcalcification (in early patients few microcalcification may be normal), stippled calcification, increased thickness of skin due to lymphoedema and nipple retraction may be seen. Fine-needle aspiration cytology was done with 23-gauge needle and 20 $\mathrm{mL}$ syringe. The lump was held firmly between fingers and thumb. Needle was passed into lump and with negative pressure continuous aspiration was done until adequate material came out through the needle. Needle with syringe was removed without negative pressure. Material was collected on a slide. Minimum 6 aspirations were done. Smear was prepared using $100 \%$ alcohol. Cytology was studied after staining with Giemsa and Papanicolaou stains. FNAC is least painful, can be done on an OPD basis, reliable and cheaper. Malignant deposits will not occur along FNAC track.

\section{Ethical Considerations}

The study was started after taking approval from Institutional Ethics Committee for Research on Human Subjects. Throughout the study, ethical considerations were followed strictly. Confidentiality was ensured. The patients were enrolled after written informed consent was obtained from patient and care taken of patient in their local language (mother tongue). Patient and care taker of patient were informed about the nature and purpose of the study. Before entry into the study, the investigator explained to the subjects about the aims and objectives of the study. Patient or caregiver were informed that their participation was voluntary and that they could withdraw consent to participate at any time. They were informed that choosing not to participate would not affect their care and the subjects would receive the proper treatment of his/her disease. The subjects or legally acceptable representative were given sufficient time to read the informed consent form and the opportunity to ask questions. If the subject or relative were unable to read or write informed consent, then investigator read and explained all written information. After this explanation and before entry to the study, consent was appropriately recorded by means of the subject's signature or thumb impression. Subjects who did not give consent to participate were not included in the study. In summary following ethical considerations were observed-

1. Before starting the study, approval for this study was obtained from the Institutional Ethics Committee for research on human subjects.

2. Written informed consent was obtained from each subject interviewed after asking them to go through the subject information sheet printed in Hindi language (in which subjects were well versed) and a verbal explanation by the interviewer.

3. Confidentiality of the information provided was maintained.

\section{Statistical Methods in Methodology}

The data were collected, and entries were made, and analysis was carried out using statistical SPSS version 23 software. Analysis was studied using Chi-square test. Sensitivity, specificity, NPV and PPV were also carried out in each category of the assessment criteria like clinical assessment, ultrasonography, mammography and FNAC. Sensitivity is considered as proportion of persons with the diseases who test positive in the screen. Specificity is the proportion of persons who do not have the disease that test negative in the screening test. The PPV is the proportion of persons who test positive that actually have the diseases. NPV is the proportion testing negative that do not have the disease. Statistically significant $\mathrm{p}$ value of less than 0.05 was considered statistically significant. P-value less than 0.01 was considered as statistically very significant and p-value of less than 0.001 was considered as statistically extremely significant.

\section{RESULTS}

The study was performed in Surgery Department in SGT Medical College, SGT University, Budhera, Gurugram, Haryana, over a period of 2 years 3 months from December 2015 to March 2018. A total of 180 patients were studied. A 
detailed history was taken, focused clinical examination done, USG, mammography and FNAC were performed. The results were evaluated. Our maximum patients were in the age group of 30 to 39 followed by age group 20 to 29 . Constituting $41.0 \%$ and $24.3 \%$ respectively (Table 2 ). $80 \%$ patients were from rural area and 20\% from urban area (Table 2). One hundred and sixty one (88.9\%) were premenopausal and 19 $(10.1 \%)$ were postmenopausal (Table 3 ). Out of total patients $126(70 \%)$ were married and $54(30 \%)$ were unmarried (Table 3). Breast swelling was most common presenting feature in 173 (96.0\%) patients. Swelling and pain was in $5(2.8 \%)$ patients. Swelling and retraction was in $1(0.6 \%)$ patient. Retracted nipple was found in $2(1.1 \%)$ patients. Nipple discharge was there in $2(1.1 \%)$ patients. Erythema of skin was in $3(1.7 \%)$ patients. Puckering was present in $2(1.1 \%)$ patients. Palpable axillary lymph nodes were present in $5(2.8 \%)$ patients. There was family history of carcinoma breast in $4(2.1 \%)$ patients (Table 4$)$. Right side breast was involved in maximum patients (106 patients, 58.9\%) (Table $5)$. Upper and outer quadrant was most commonly involved (86 patients, 48.0\%) (Table 5). All the patients underwent ultrasonography. Fibroadenoma was present in maximum patients (116 patients, 64.4\%). Fibroadenosis was in 29 patients, galactocele 2 patients, breast abscess 20 patients, lactation changes in 1 patient and cyst was present in 2 patients. Solid mass finding was in $5(2.8 \%)$ patients. Solid mass with irregular margin were present in $4(2.2 \%)$ patients. Loss of normal architecture were found in $1(0.6 \%)$ patient (Table 6). Mammography done only in married patients revealed well-circumscribed mass with regular margins in $113(90.0 \%)$ patients. Density lesion with microcalcification was found in $3(2.3 \%)$ patients. Density with irregular margins and speculation was found in 7 (5.4\%) patients. Density lesion with microcalcification, irregular margins and spiculation was found in $3(2.3 \%)$ patients (Table 7). FNAC was done in all patients. Fibroadenoma was found in maximum number of patients $(114,63.2 \%)$. Duct carcinoma was found in $11(6.1 \%)$ patients (Table 8). On histopathology fibroadenoma was found in 108 (72.0\%) patients, fibroadenosis was found in $5(3.3 \%)$ patients, breast abscess was found in $21(14.0 \%)$ patients, inflammatory changes was found in $1(0.7 \%)$ patient and infiltrating ductal carcinoma of breast were found in $15(10.0 \%)$ patients (Table 9). There was a concordance of $97.3 \%$, PPV of $80 \%$, NPV of 99.3\%, 92.3\% sensitivity and $97.8 \%$ specificity on physical examination. There was a significant P-value of 0.0000 . In case of mammography corresponding values were $98.1 \%$, $86.7 \%, 100 \%, 97.9 \%$ and $100 \%$ respectively for concordance, PPV, NPV, sensitivity and specificity respectively. Again, there was a significant p-value $(0.000)$. So far as USG is concerned the values were $96.7 \%, 66.7 \%, 100 \%, 100 \%$ and $97.1 \%$ respectively for concordance, PPV, NPV, sensitivity and specificity respectively. There was again a significant $\mathrm{p}$-value of 0.000 . On FNAC, the results were like this. Concordance $97.3 \%$, PPV $73.3 \%$, NPV 100\%, sensitivity $100 \%$ and specificity $97.1 \%$ with a significant p-value of 0.000 . The results of all the above modalities were on comparison with histopathology examination. The final results for triple assessment were like this. Concordance 99.3\%, PPV 93.3\%, NPV $100 \%$, sensitivity $100 \%$ and specificity $99.3 \%$ and a significant p-value of $0.000 \%$.

\begin{tabular}{|c|c|c|}
\hline $\begin{array}{c}\text { Slight-to- } \\
\text { Moderate Risk }\end{array}$ & $\begin{array}{c}\text { Moderate-to- } \\
\text { High Risk }\end{array}$ & Very High Risk \\
\hline $\begin{array}{c}\text { Florid } \\
\text { hyperplasia }\end{array}$ & Age > 60 years & Therapeutic radiation \\
\hline $\begin{array}{c}\text { Solid duct } \\
\text { papilloma }\end{array}$ & LCIS & $\begin{array}{c}\text { Family history of breast } \\
\text { cancer in two 1st degree } \\
\text { relatives }\end{array}$ \\
\hline $\begin{array}{c}\text { Obesity, } \\
\text { alcohol, HRT }\end{array}$ & $\begin{array}{c}\text { History of } \\
\text { DCIS }\end{array}$ & $\begin{array}{c}\text { Family history of breast } \\
\text { and ovarian cancer }\end{array}$ \\
\hline Nulliparity & $\begin{array}{c}\text { Cancer on one } \\
\text { side breast }\end{array}$ & $\begin{array}{c}\text { Mutation of tumour } \\
\text { suppressor genes } \\
\text { BRCA1/BRCA2 }\end{array}$ \\
\hline $\begin{array}{c}\text { Early menarche, } \\
\text { late menopause }\end{array}$ & & \multicolumn{2}{|c|}{ Table 1. Showing Risk Factors Classification } \\
\hline \multicolumn{2}{|c}{} \\
\hline
\end{tabular}

\begin{tabular}{|c|c|c|}
\hline Age (Year) & No. of Patients & Percentage \\
\hline$<20$ & 15 & 8.1 \\
\hline $20-29$ & 44 & 24.3 \\
\hline $30-39$ & 73 & 41.0 \\
\hline $40-49$ & 30 & 16.6 \\
\hline$>50$ & 18 & 10.0 \\
\hline Rural & 135 & 80.0 \\
\hline Urban & 45 & 20.0 \\
\hline \multicolumn{3}{|c|}{$\begin{array}{c}\text { Table 2. Showing Age and Demographic Distribution } \\
\text { of the Study Cases (No. of Patients-180) }\end{array}$} \\
\hline
\end{tabular}

\begin{tabular}{|c|c|c|c|}
\hline $\begin{array}{c}\text { Age (Year) of } \\
\text { Menarche }\end{array}$ & $\begin{array}{c}\text { No. of } \\
\text { Patients }\end{array}$ & Percentage \\
\hline $\begin{array}{c}\text { Menstruation } \\
\text { status }\end{array}$ & Pre-menopausal & 161 & 88.9 \\
\cline { 2 - 4 } & Post-menopausal & 19 & 10.1 \\
\hline \multirow{2}{*}{ Marital status } & Married & 126 & 70.0 \\
\cline { 2 - 4 } & Unmarried & 54 & 30.0 \\
\hline \multicolumn{3}{|c|}{ Table 3. Showing Menstrual Profile and Marital } \\
Status of Patient \\
\hline
\end{tabular}

\begin{tabular}{|c|c|c|}
\hline Clinical Feature & $\begin{array}{c}\text { No. of } \\
\text { Patients }\end{array}$ & Percentage \\
\hline Presence of lump & 173 & 96.0 \\
\hline Lump along with retraction & 5 & 2.8 \\
\hline Lump with pain & 1 & 0.6 \\
\hline Retraction of nipple & 2 & 1.1 \\
\hline Presence of discharge from nipple & 2 & 1.1 \\
\hline Erythema of skin & 3 & 1.7 \\
\hline Presence of puckering & 2 & 1.1 \\
\hline Presence of axillary lymph nodes & 5 & 2.8 \\
\hline $\begin{array}{c}\text { Presence of history of carcinoma } \\
\text { breast in family }\end{array}$ & 4 & 2.1 \\
\hline $\begin{array}{c}\text { Table 4. Showing Clinical Feature of Patients } \\
\text { (No. of Patients= 180) }\end{array}$ \\
\hline \multicolumn{3}{|c|}{} \\
\hline \multicolumn{2}{|c|}{} \\
\hline
\end{tabular}

\begin{tabular}{|c|c|c|c|}
\hline \multicolumn{2}{|c|}{ Characteristics } & No. of Patients & Percentage \\
\hline \multirow{3}{*}{ Side involved } & Left & 72 & 40.0 \\
\cline { 2 - 4 } & Right & 106 & 58.9 \\
\cline { 2 - 4 } & Bilateral & 2 & 1.1 \\
\hline \multirow{4}{*}{ Quadrant } & Central & 19 & 10.6 \\
\cline { 2 - 4 } & Upper outer & 86 & 48.0 \\
\cline { 2 - 4 } & Upper inner & 33 & 18.0 \\
\cline { 2 - 4 } & Lower outer & 21 & 11.2 \\
\cline { 2 - 4 } & Lower inner & 21 & 11.2 \\
\hline \multirow{3}{|c|}{ Table 5. Showing Side and Quadrants of the Affected } \\
Breast in the Studied Patients \\
\hline
\end{tabular}




\begin{tabular}{|c|c|c|}
\hline USG Impression & No. of Patients & Percentage \\
\hline Fibroadenoma & 116 & 64.4 \\
\hline Fibroadenosis & 29 & 16.0 \\
\hline Galactocele & 2 & 1.1 \\
\hline Breast abscess & 20 & 11.2 \\
\hline Lactational changes & 1 & 0.6 \\
\hline Solid mass & 5 & 2.8 \\
\hline Solid mass with irregular margins & 4 & 2.2 \\
\hline Loss of normal architecture & 1 & 0.6 \\
\hline Cyst & 2 & 1.1 \\
\hline Table 6. Showing Ultrasonographic Impression of the Breast Lumps in the Patients (No. of Patients= 180) \\
\hline
\end{tabular}

\begin{tabular}{|c|c|c|}
\hline Findings & No. of Patients & Percentage \\
\hline Well circumscribed mass with regular margins & 135 & 91.3 \\
\hline Density lesion with microcalcification & 3 & 2.0 \\
\hline Density lesion with irregular margins and spiculation & 7 & 4.7 \\
\hline Density lesion with microcalcification, irregular margins and spiculation & 3 & 2.0 \\
\hline Total & $\mathbf{1 4 8}$ & 100 \\
\hline
\end{tabular}

\begin{tabular}{|c|c|c|}
\hline FNAC & No. of Patients & Percentage \\
\hline Fibroadenoma & 114 & 63.2 \\
\hline Fibroadenosis & 30 & 16.6 \\
\hline Galactocele & 2 & 1.1 \\
\hline Breast abscess & 23 & 13.0 \\
\hline Ductal carcinoma & 11 & 6.1 \\
\hline Total & $\mathbf{1 8 0}$ & $\mathbf{1 0 0}$ \\
\hline \multicolumn{2}{|c|}{ Table 8. Showing Results of FNAC in the Studied Patients } \\
\hline
\end{tabular}

\begin{tabular}{|c|c|c|}
\hline Findings & No. of Patients & Percentage \\
\hline Fibroadenoma & 108 & 72.0 \\
\hline Fibroadenosis & 5 & 3.3 \\
\hline Breast abscess & 21 & 14.0 \\
\hline Infiltrating ductal carcinoma of breast & 15 & 10.0 \\
\hline Inflammatory changes & 1 & 0.7 \\
\hline Table 9. Showing Results of Histopathology in the Studied Patients (No. of Patients= 150) \\
\hline
\end{tabular}

\begin{tabular}{|c|c|c|c|c|c|c|}
\hline \multirow{2}{*}{\multicolumn{2}{|c|}{ Modality of Triple Assessment }} & \multicolumn{2}{|c|}{ Histopathology } & \multirow{3}{*}{$\begin{array}{c}\begin{array}{c}\text { No. of } \\
\text { Patients }\end{array} \\
13\end{array}$} & \multirow{3}{*}{\begin{tabular}{|c|}
$\begin{array}{c}\text { Positive Predictive } \\
\text { Value }\end{array}$ \\
$80 \%$ \\
\end{tabular}} & \multirow{3}{*}{\begin{tabular}{|c|}
$\begin{array}{c}\text { Negative Predictive } \\
\text { Value }\end{array}$ \\
$99.3 \%$
\end{tabular}} \\
\hline & & \multirow{2}{*}{$\begin{array}{l}\text { Malignant } \\
12(92.3 \%)\end{array}$} & \multirow{2}{*}{$\begin{array}{c}\text { Benign } \\
1(7.7 \%)\end{array}$} & & & \\
\hline Physical & Malignant (+) & & & & & \\
\hline examination & Benign (-) & $3(2.2 \%)$ & 134 & 137 & & \\
\hline Total & & 15 & 135 & 150 & & \\
\hline
\end{tabular}

\begin{tabular}{|c|c|c|c|c|c|c|}
\hline \multirow{2}{*}{ Modality of Triple Assessment } & \multicolumn{2}{|c|}{ Histopathology } & \multirow{2}{*}{ No. of Patients } & $\begin{array}{c}\text { Positive Predictive } \\
\text { Value }\end{array}$ & $\begin{array}{c}\text { Negative Predictive } \\
\text { Value }\end{array}$ \\
\cline { 2 - 7 } Mammography & Malignant & Benign & & $86.7 \%$ & $100 \%$ \\
\cline { 2 - 7 } & Malignant & $13(100 \%)$ & 0 & 13 & & \\
\hline Tonign & $2(2.1 \%)$ & $92(97.9)$ & 94 & & \\
\hline \multicolumn{7}{|c|}{ Table 11. Showing Results of Mammography in Triple Assessment } \\
\hline
\end{tabular}

\begin{tabular}{|c|c|c|c|c|c|c|}
\hline \multirow{2}{*}{ Modality of Triple Assessment } & \multicolumn{2}{|c|}{ Histopathology } & \multirow{2}{*}{$\begin{array}{c}\text { No. of } \\
\text { Patients }\end{array}$} & $\begin{array}{c}\text { Positive Predictive } \\
\text { Value }\end{array}$ & $\begin{array}{c}\text { Negative Predictive } \\
\text { Value }\end{array}$ \\
\cline { 3 - 6 } & & Malignant & Benign & 10 & $66.7 \%$ & $100 \%$ \\
\hline \multirow{2}{*}{ USG } & Malignant & $10(100 \%)$ & 0 & 10.70 & \\
\cline { 2 - 6 } & Benign & $5(3.6 \%)$ & $135(96.4)$ & 140 & & \\
\hline \multirow{2}{*}{ Total } & & $\mathbf{1 5}$ & $\mathbf{1 3 5}$ & $\mathbf{1 5 0}$ & & \\
\end{tabular}

Table 12. Showing Results of USG in Triple Assessment

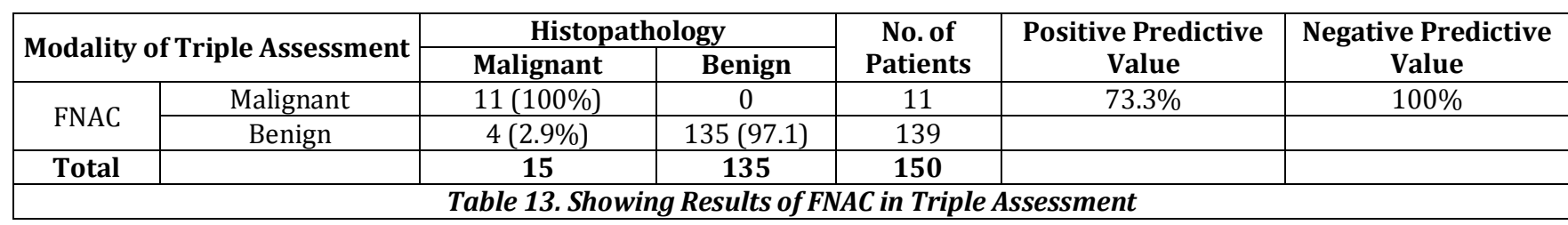




\section{DISCUSSION}

This study of evaluation of triple assessment for diagnosis of breast cancer in a tertiary centre was performed in Surgery Department in SGT Medical College, SGT University, Budhera, Gurugram, Haryana, over a period of 2 years 3 months from December 2015 to March 2018. A total of 180 patients were studied. A combination of three tests (Triple assessment) i.e. clinical assessment- history including (age) and examination; radiological imaging US/ mammography (after 40 years); cytological or historical analysis FNAC/ core biopsypathology. Triple assessment is taken as positive if any of the three components is positive and negative only if all of its components are negative for malignancy.

As per physical examination, malignant disease was in favour of 13 patients. Histopathology revealed malignancy in 12 patients. Benign disease was considered in 137 patients on physical examination. On histopathology, benign disease was confirmed in 134 patients and the remaining 3 patients diagnosed as malignant (Table 10). Our results were similar to Yang et al (1996). ${ }^{7}$ The results of mammography revealed positive predictive value of $86.7 \%$ and negative predictive value of $100 \%$ with significant $p$-value of 0.000 . The results are comparable with Shetty et al (2003).8 Marteli et al $(1990)^{9}$ also gave similar results. Kaufman et al (1994)10 found the sensitivity of mammography as $89.0 \%$ and specificity as $73.0 \%$. The results of Steinberg et al (1996) ${ }^{11}$ and Yang et al (1996) ${ }^{7}$ were also similar. Ultrasonography was in favour of malignancy in 10 patients, who were all found to be malignant on histopathology. On ultrasonography 140 cases were diagnosed as benign, of which 5 were malignant on histopathology. Thus, the sensitivity was $100 \%$, specificity was $96.4 \%$, positive predictive value was $66.7 \%$ and negative predictive value was $100 \%$. ' $\mathrm{P}$ ' value was significant (0.000). Our results were comparable to Pande et al (2003)12 and Yang et al (1996).6

In 11 patients, FNAC revealed malignancy. All these patients were malignant as per histopathology also; however, 4 patients who were told benign by FNAC were actually found to be malignant as per histopathology. Sensitivity of FNAC was $100 \%$, specificity was $97.1 \%$, positive predictive value was $86.7 \%$ and negative predictive value was $100 \%$. 'P' value was significant $(0.000)$. Our results of FNAC were similar to Marteli et al (1990), ${ }^{9}$ Kaufman et al (1994), ${ }^{10}$ Steinberg et al (1996), ${ }^{11}$ Reinikainen et al (1990) ${ }^{13}$ and Ariga et al (2002). ${ }^{14}$ The results of Mohammad et al (2005) ${ }^{15}$ of FNAC were $100 \%$ for positive predictive value, $90.6 \%$ for sensitivity and $100 \%$ for specificity. Thus, we have in triple assessment the concordance of $99.3 \%$, specificity of $100 \%$, sensitivity of $99.3 \%$, positive predictive value of $99.3 \%$, negative predictive value of $100 \%$ and a significant $p$-value $(0.000)$.

\section{CONCLUSION}

We have found that in diagnosis of breast cancer in our tertiary centre, the triple assessment was found to be very useful in evaluating patients of breast lumps with an overall accuracy of $99.3 \%$. When clinical examination, mammography, USG and FNAC are all negative for malignancy in a patient with breast lump, the patient is unlikely to have malignancy and need for histology can be obviated and patient can be safely observed.

\section{ACKNOWLEDGEMENTS}

I would like to acknowledge the books, Farquharson's Textbook of Operative General Surgery, 9th Edition, Margaret
Farquharson; SRB's Manual of Surgery $5^{\text {th }}$ Edition by Sriram Bhat M; Bedside Clinics in Surgery, $3^{\text {rd }}$ Edition by Makhan Lal Saha.

\section{REFERENCES}

[1] Farquharson M, Hollingshead J, Moran B. Farquharson's Textbook of operative general surgery. $9^{\text {th }}$ edn. London: CRC Press 2005.

[2] Bland KI, Beenken S, Copeland EM III. The breast. Schwartz's Princip Surg. 2005;16:454.

[3] Iglehart JD, Kaelin CM. Diseases of the breast. In: Sabiston Text book of surgery. Vo. 1. 17th edn. 2004: p. 877.

[4] Saha ML. Bedside clinical in surgery. $3^{\text {rd }}$ edn. New Delhi: Jaypee Brothers Medical Publishers 2018.

[5] Tiwari PK, Ghosh S, Agrawal VK. Diagnostic accuracy of mammography and ultrasonography in assessment of breast cancer. International Journal of Contemporary Medical Research 2017;4(1):81-3.

[6] Bhat SM. SRB's Manual of surgery. $5^{\text {th }}$ edn. New Delhi: Jaypee Brothers Medical Publishers 2016.

[7] Yang WT, Mok CO, King W, et al. Role of high frequency ultrasonography in the evaluation of palpable breast masses in Chinese women: alternative to mammography? J Ultrasound Med 1996;15(9):63744 .

[8] Shetty MK, Shah YP, Sharman RS. Prospective evaluation of the value of combined mammographic and Sonographic assessment in patients with palpable abnormalities of the breast. J Ultrasound Med 2003;22(3):263-8.

[9] Martelli G, Pilotti S, Coopmans de Yoldi CG, et al. Diagnostic efficacy of physical examination, mammography, fine needle aspiration cytology (tripletest) in solid breast lumps: an analysis of 1,708 consecutive cases. Tumouri 1990;76(5):476-9.

[10] Kaufman Z, Shpitz B, Shapiro M, et al. Triple approach in the diagnosis of dominant breast masses: combined physical examination, mammography and fine-needle aspiration. J Surg Oncol 1994;56(4):254-7.

[11] Steinberg JL, Trudeau ME, Ryder DE, et al. Combined fine-needle aspiration, physical examination and mammography in the diagnosis of palpable breast masses: their relation to outcome for women with primary breast cancer. Can J Surg 1996;39(4):302-11.

[12] Pande AR, Lohani B, Sayami P, et al. Predictive value of ultrasonography in the diagnosis of palpable breast lump. Kathmandu Univ Med J (KUMJ) 2003;1(2):7884.

[13] Reinikainen HT, Rissanen TJ, Piippo UK, et al. Contribution of ultrasonography and fine-needle aspiration cytology to the differential diagnosis of palpable solid breast lesions. Acta Radiol 1999;40(4):383-9.

[14] Ariga R, Bloom K, Reddy VB, et al. Fine-needle aspiration of clinically suspicious palpable breast masses with histopathologic correlation. Am J Surg 2002;184(5):410-13.

[15] Mohammed AZ, Edino ST, Ochicha 0, et al. Value of fine needle aspiration biopsy in preoperative diagnosis of palpable breast lumps. Ann Afric Medi 2005;4(1):1922. 